\title{
PReS-FINAL-1010: circulating micrornas in traps
}

\author{
OM Lucherini ${ }^{1 *}, M$ Ferracin ${ }^{2}$, V Fulci ${ }^{3}, M$ McDermott ${ }^{4}, G$ Merlini ${ }^{5}$, I Muscari ${ }^{1}$, F Magnotti ${ }^{1}$, LJ Dickie ${ }^{4}$, M Galeazzi $^{1}$, \\ M Negrini ${ }^{2}, C T$ Baldari $^{6}$, L Obici $^{5}$, R Cimaz $^{7}$, L Cantarini $^{1}$ \\ From 20th Pediatric Rheumatology European Society (PReS) Congress \\ Ljubljana, Slovenia. 25-29 September 2013
}

\section{Introduction}

To the best of our knowledge circulating miRNAs in TRAPS, as well as in other monogenic autoinflammatory disorders have never been investigated.

\section{Objectives}

To evaluate circulating microRNAs (miRNAs) levels in patients with tumor necrosis factor-receptor associated periodic syndrome (TRAPS), in comparison to healthy controls, and to correlate their levels to parameters of disease activity and/or disease severity.

\section{Methods}

Expression levels of circulating miRNAs were measured by Agilent microarrays in 29 serum samples from 15 TRAPS patients carrying mutations known to be associated with high disease penetrance and 8 healthy controls. Differentially expressed and clinically relevant miRNAs were detected using GeneSpring GX software.

\section{Results}

We identified a 6 miRNAs signature able to discriminate TRAPS from healthy controls. Moreover, 4 miRNAs were differentially expressed between patients treated with the interleukin (IL)-1 receptor antagonist anakinra and untreated patients. Of these, miR-92a-3p expression was found to be reduced in untreated patients, while its expression levels were similar to healthy controls in samples obtained during anakinra treatment. MiR-92b levels were inversely correlated with the number of fever attacks/year during the $1^{\text {st }}$ year from the index attack of TRAPS, while miR-377-5p levels were positively correlated with serum amyloid A (SAA) circulating levels.

\section{Conclusion}

Serum miRNAs levels show a baseline pattern in TRAPS, and may serve as potential markers of response to therapeutic intervention.

\section{Disclosure of interest}

None declared.

\section{Authors' details}

${ }^{1}$ Department of Medical Sciences, Surgical and Neuroscience. Rheumatology Unit., università di Siena, Siena, Italy. ${ }^{2}$ Laboratory for Technologies of Advanced Therapies (LTTA) and Department of Morphology, Surgery and Experimental Medicine, University of Ferrara, Ferrara, Italy. ${ }^{3}$ Dipartimento di Biotecnologie Cellulari ed Ematologia, Sezione di Genetica Molecolare, Sapienza, Università di Roma, Roma, Italy. ${ }^{4}$ Leeds Institute of Rheumatic and Musculoskeletal Medicine, Leeds, UK. ${ }^{5}$ Amyloid Research and Treatment Center, Fondazione IRCCS Policlinico San Matteo, and Department of Molecular Medicine, University of Pavia, Pavia, Italy. ${ }^{6}$ Department of Life Sciences, Università di Siena, Siena, Italy. ${ }^{7}$ Department of Pediatrics, Rheumatology Unit, Anna Meyer Children's Hospital and University of Florence, Florence, Italy.

Published: 5 December 2013

doi:10.1186/1546-0096-11-S2-P8

Cite this article as: Lucherini et al:: PReS-FINAL-1010: circulating micrornas in traps. Pediatric Rheumatology 2013 11(Suppl 2):P8.

Submit your next manuscript to BioMed Central and take full advantage of:

- Convenient online submission

- Thorough peer review

- No space constraints or color figure charges

- Immediate publication on acceptance

- Inclusion in PubMed, CAS, Scopus and Google Scholar

- Research which is freely available for redistribution 